\title{
Investigation of spray agglomeration process in continuously operated horizontal fluidized bed
}

\author{
Du, J. ${ }^{\text {a*}}$; Bück, A. ${ }^{\text {a,b}}$; Tsotsas, E. ${ }^{\text {a }}$ \\ ${ }^{\text {a }}$ NaWiTec, Thermal Process Engineering, Otto von Guericke University Magdeburg. \\ b Institute of Particle Technology, FAU Erlangen-Nuremberg, Cauerstraße 4, D-91058 Erlangen, \\ Germany.
}

*E-mail of the corresponding author: jiajie.du@ovgu.de

\begin{abstract}
Spray fluidized bed agglomeration is an important process in particle formation and is widely used in the chemical, pharmaceutical and food industry. In this study a continuously operated horizontal fluidized bed is employed to obtain a continuous agglomeration process. It is conducted with glass beads $\left(d_{s t}=200 \mu \mathrm{m}\right)$ and water-based binder hydroxy-propyl-methylcellulose (HPMC) sprayed by three top nozzles. The steady state is reached and samples are taken periodically and analyzed. The influence of fluidization air temperature and configurations of internal weirs are studied.
\end{abstract}

Keywords: horizontal fluidized bed, spray agglomeration, continuous process 


\section{Introduction}

Size enlargement processes have the purpose of changing the physical properties of powders in order to meet desired product specifications such as size, shape, flowability, density, solubility or porosity [1]. Among various heavily used apparatuses, spray fluidized bed agglomerator is an important one and widely used in the chemical, pharmaceutical and food industry. The most significant advantage of this apparatus is that it allows the combination of binder dispersion and drying in a single process [2]. In the agglomeration process, fluidized particles are wetted by spraying a liquid; agglomeration occurs when a wet particle collides with another particle forming initially a liquid bridge which solidifies by drying. A lot of attention has been paid on the study of this process but most of them are batch operated process. Among them the effect of process parameters such as binder addition rate, binder viscosity, fluidization velocity, air temperature, the morphology of agglomerates as well as the simulation based on population balance equation and Monte Carlo method have been studied [3,4,5,6]. However, many producers look for a continuous process for economic reasons instead of a batch process with high labor and dead-time. In this study, a horizontal fluidized bed is employed because it has serval advantages such as the possibility to control different processes in separated chambers and possibility to control particle residence time distribution.

\section{Materials and Methods}

\subsection{Plant and materials}

In this paper, the agglomeration process was performed in a continuously operated horizontal fluidized bed (GF/Procell 20, Glatt GmbH, Weimar, Germany). A schematic flow diagram of the experimental fluidized bed is shown in Fig. 1. The dimensions of the horizontal fluidized bed are $1 \mathrm{~m}$ in length and $0.2 \mathrm{~m}$ in width. By installation of internal weirs, the bed can be separated into four chambers. With different settings of internal weirs, underflow and overflow can be achieved. To control the bed height, different heights of outlet weirs can be applied. The particles inlet speed was controlled by a twin screw feeder together with a rotary valve at the end of the feeding pipe which was used to isolate the bed from the atmosphere. The outlet was controlled by a rotary valve with constant rotation speed. The pulse injection of the tracer used in the residence time distribution measurement is enabled by an additional sewer port in the steady state of the system. The fluidization air was provided by two fans; one was at inlet and one at outlet. By adjusting the power of the two fans, the pressure inside the bed can be controlled. The fluidization air was heated by an electrical heater being separated into four pipes and entering the bed. The air speed and temperature in each pipes can be controlled by the open ratio of the two valves separately. Process parameters such as the fluidization air speed, the heater temperature, the open ratio 
of valves, the spraying rate and etc. were controlled Distributed Control System station. The cross section of the upper side of the process chamber was expanded to reduce gas velocity and, thus, enforce the return of entrained particles in the fluidized bed. For the spraying system, maximum three top spray nozzles provided by Düsen-Schlick GmbH, Untersiemau, Germany, model 940/3 with orifice diameter $0.8 \mathrm{~mm}$, two-fluid nozzle, could be used. The nozzles are placed at a height of $320 \mathrm{~mm}$ from the distributor. The spray rate was controlled by a piston pump and the atomizing air pressure was controlled by an adjustable valve.

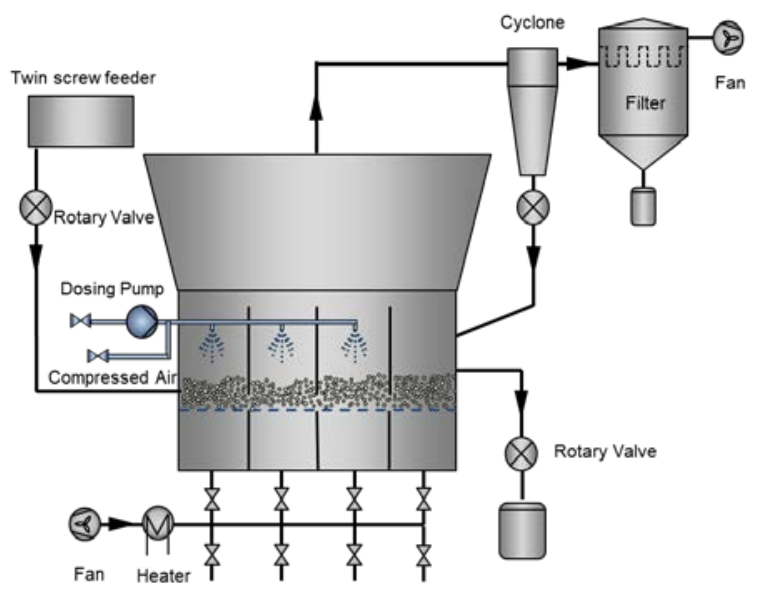

Fig. 1 Schematic representation of the plant GF/Procell 20 (Glatt GmbH).

The particles used for the experiments were glass beads (Sigmund Lindner GmbH, Germany), had a high sphericity of 0.89 and density $2500 \mathrm{~kg} / \mathrm{m}^{3}$, and were nearly monodisperse. Measurements by Camsizer (Retsch Technologies GmbH, Haan, Germany) resulted in a very narrow range size distribution of the primary particles, with diameters between $150 \mu \mathrm{m}$ to $320 \mu \mathrm{m}$ and the Sauter diameter of $200 \mu \mathrm{m}$. The binder used was hydroxy-propyl-methyl-cellulose (HPMC, trade name Pharmacoat 606, from Shin-Etsus, Japan) water solution.

\subsection{Experimental parameters}

To study the influence of process parameters, seven experiments were carried out, denoted by No. 1-7 (Table 1). Reference Exp. NO. 2 was defined and then only one of the process variables was changed at a time. For all experiment, the feed rate was controlled at 400 
$\mathrm{g} / \mathrm{min}$ and fluidization air speed at $1.1 \mathrm{~m} / \mathrm{s}$. The binder used was $4 \mathrm{wt} \%$ and relative air pressure in the nozzle was 1 bar. The influence of fluidization air temperature was studied by running experiments with different air temperature at $100,80,70$ and $60^{\circ} \mathrm{C}$. To study the influence of the configuration of internal wires, three internal weirs were employed and the gap height between the weirs and the air distribution plate were 10 and $5 \mathrm{~mm}$. For all experiment, the outlet weir height was $200 \mathrm{~mm}$.

To start the experiments, the plant was heated to the needed temperature then the feeder was started for the feeding. Apart from this metered feed, an initial feed of $6 \mathrm{~kg}$ of glass beads was fed instantly to promote the growth of the bed. The steady state was reached when the inlet and outlet mass flow rate of the particles were equal. After this stage, the binder pump was started. Samples were collected at the outlet periodically and used for analysis. The process time in each experiment was 130 -150 min.

Table 1. Main experimental parameters

\begin{tabular}{lcccc}
\hline $\begin{array}{c}\text { Exp. } \\
\text { NO. }\end{array}$ & $\begin{array}{c}\text { Inlet Air } \\
\text { Temperature } \\
\mathbf{T}_{\mathbf{a}}\left[{ }^{\circ} \mathrm{C}\right]\end{array}$ & $\begin{array}{c}\text { Spray rate } \dot{\mathbf{m}}_{\mathbf{b}} \\
{[\mathbf{g} / \mathbf{m i n}]}\end{array}$ & $\begin{array}{c}\text { Number of } \\
\text { internal } \\
\text { Weirs }\end{array}$ & $\begin{array}{c}\text { Gap height in } \\
\text { underflow }[\mathbf{m m}]\end{array}$ \\
\hline 1 & 100 & 72 & - & - \\
2 (Ref.) & 80 & 71 & - & - \\
3 & 70 & 73 & - & - \\
4 & 60 & 71 & - & 10 \\
5 & 80 & 72 & 3 & 5 \\
6 & 80 & 71 & 3 & - \\
\hline
\end{tabular}

\subsection{Experimental result analysis}

In the first set of experiments the fluidization air temperature has been varied. As Fig. 2 displays, the largest Sauter diameters of agglomerates were obtained at the lowest air temperature experiment NO.4 at air temperature $60^{\circ} \mathrm{C}$. Agglomeration rate decreased with the increase of air temperature. At lower temperature, the process took a longer time to reach the steady and the lower temperature also introduced more fluctuations because more particles stuck to the wall due to the higher moisture inside the bed. A decrease in agglomeration rate with increasing gas inlet temperature was also reported in batch operated agglomeration process [4,5]. At higher temperature binder droplets evaporate and shrink faster after having been sprayed from the nozzle, which decreases the height of sessile droplets. Some spray droplets may not even find a chance to hit the particle surface. In both cases, the number of particle collisions leading to agglomeration decreases [7]. From what showed in SEM pictures, at higher temperature despite using the same amount 
of binder, there are more dried droplets layering on the outer surface of particles, meaning that the process tends to move from agglomeration towards coating.

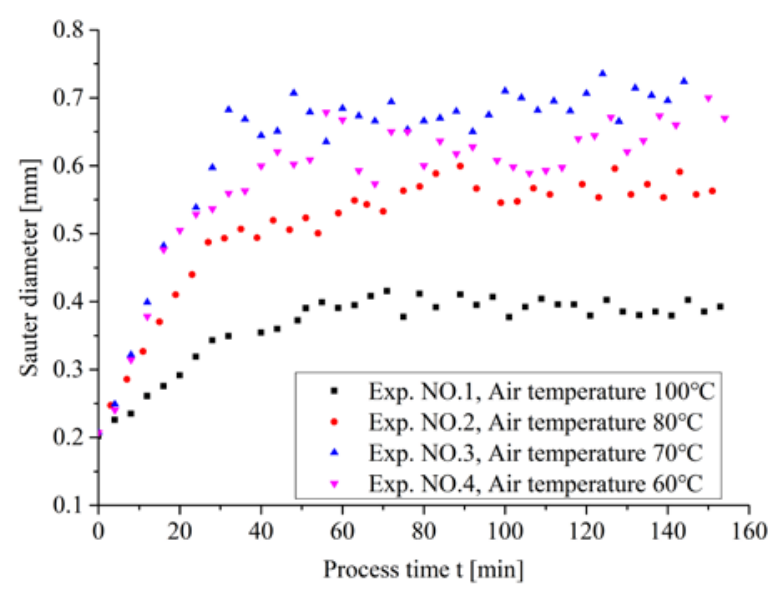

Fig. 2 Sauter diameter versus time at different air temperatures.

Fig. 3 shows the Characteristic diameters $X_{10,3}, X_{50,3}, X_{90,3}$ and bed mass change during the process. Compared to the Sauter diameter the same trend was observed that at a lower temperature a higher agglomeration rate and bigger agglomerates are achieved, combined with a wider size distribution of agglomerates at the end of the experiment. With bigger agglomerates the process needs longer time to reach the steady state. There was a fast increasing of bed mass in the first $20 \mathrm{~min}$ of spraying. Bigger agglomerates also lead to a higher bed mass. When the air temperature was 70 and $60^{\circ} \mathrm{C}$, a continuous increasing of bed mass was seen after 100-120 min which means that there is a high risk of defluidization in these two experiments.

In the second set of experiments, the internal weirs were used and the gap height was changed to see the influence of internals weirs on particle size distribution. The internal weirs are commonly used in such horizontal fluidized bed to control the flow behavior of particles. As Fig. 4 displays, the smallest Sauter diameter was achieved from the experiment with internal weirs which have the smallest gap height. During the present experiments, a slower rate of size increase was observed when the internal weirs were installed. The particle size distribution shows the internal weirs influence the flow behavior of the particles which could be shown more clearly in the residence time distribution measurement. By the installation of the weirs, more accessories were installed inside the bed which means more particles could stick. During the process, a hammer was used to knock the wall to clean the sticking particles on the walls and nozzles to prevent the formation of big lumps or the blocking of nozzles. 

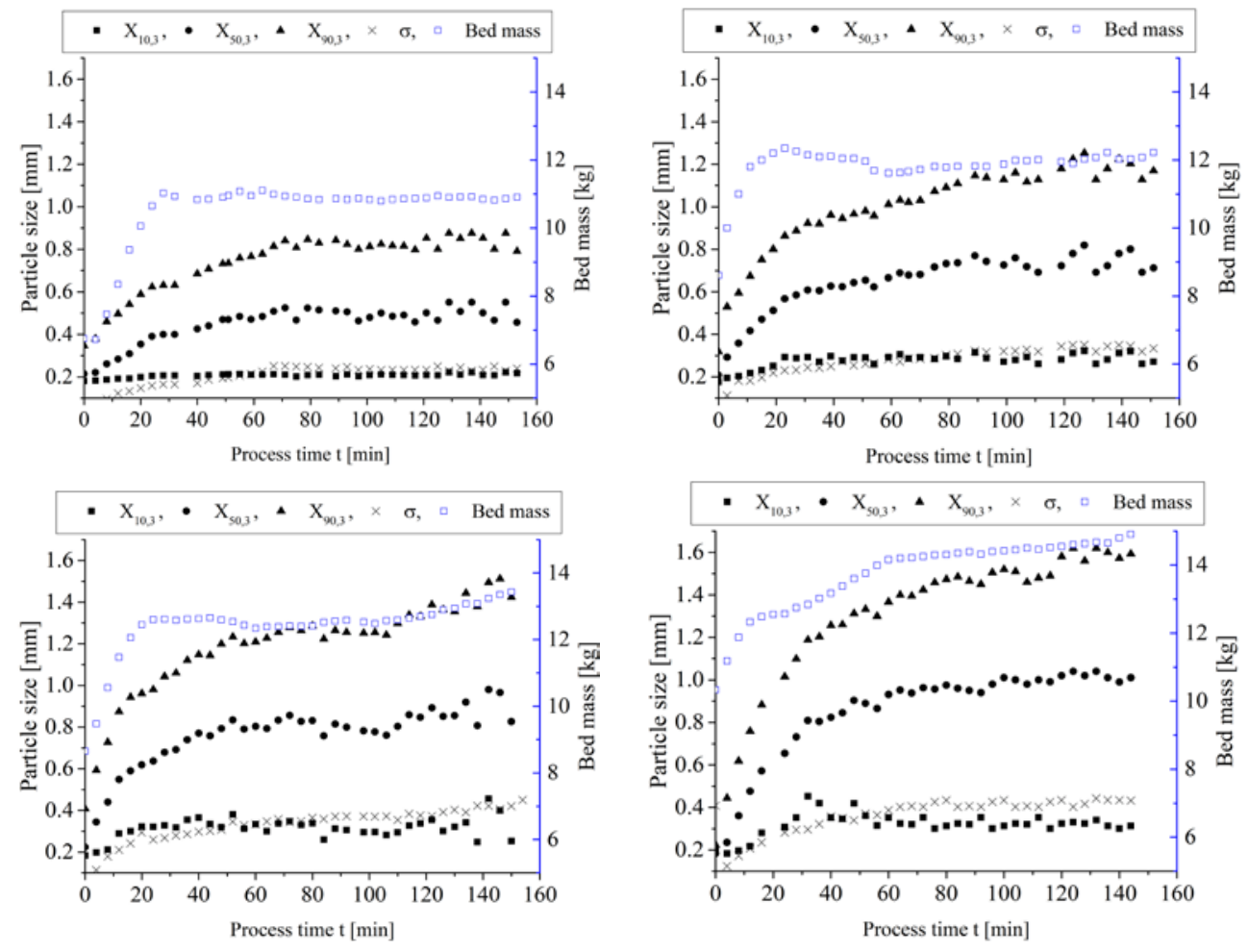

Fig. 3 Characteristic diameter $X_{10,3}, X_{50,3}$, and $X_{90,3}$, the standard deviation $\sigma$ and bed mass of experiments at temperature 100 (left, top), 80 (right, top), 70 (left, bottom) and $60^{\circ} \mathrm{C}$ (right, bottom).

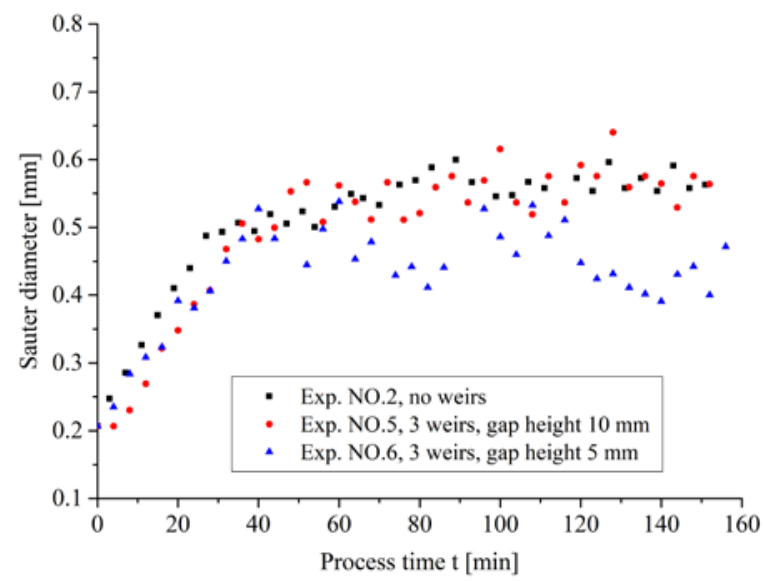

Fig. 4 Sauter diameter versus time with different internal weirs configurations. 

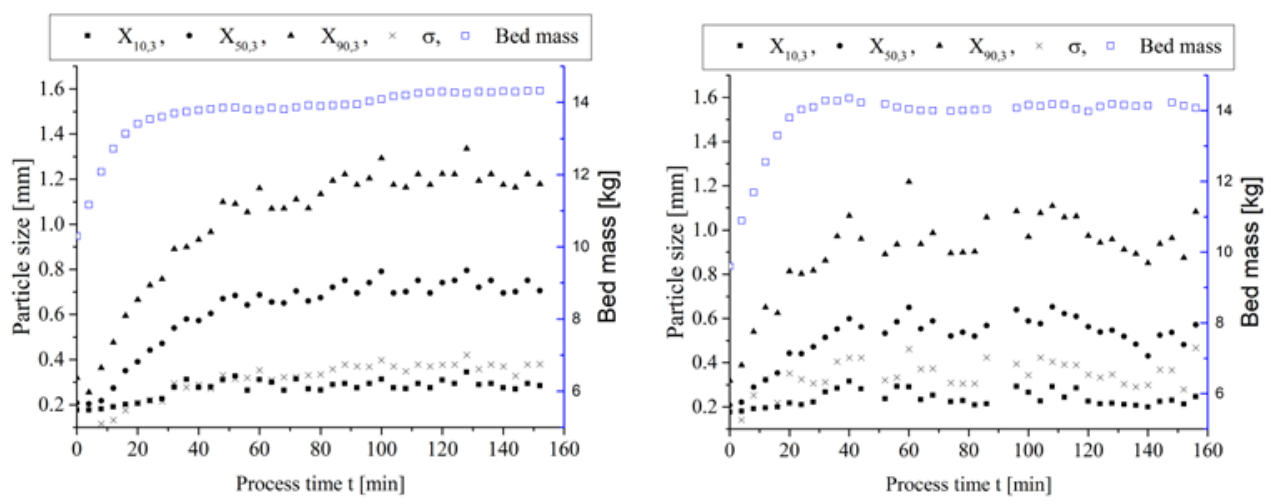

Fig. 5 Characteristic diameter $X_{10,3}, X_{50,3}$, and $X_{90,3}$, the standard deviation $\sigma$ and bed mass of experiments with internal weirs gap height $10 \mathrm{~mm}$ (left) and gap height $5 \mathrm{~mm}$ (right).

In Fig. 5, when compared to the reference experiment, it was observed that with internal weirs the starting bed mass of experiment is higher than without internal weirs because by separating process chambers, the spray has less influence on the fluidization of particles in last chamber. The internal weirs with gap height $10 \mathrm{~mm}$ have little influence on the size of agglomerates as well as on the width of size distribution. When the gap height was decreased to $5 \mathrm{~mm}$, they decreased the size of agglomerates and a higher standard deviation of particle size distribution was observed which means a wider size distribution was achieved.

\section{Conclusions}

In this work, a continuously operated horizontal fluidized bed was used to conduct a spray agglomeration. The influence fluidization air temperature and configuration of internal weirs is presented. It was observed that an increase of air temperature results in decrease of agglomerate size and the width of size distribution combine with more fluctuations during the process. The internal weirs with gap height $10 \mathrm{~mm}$ have little influence on the size distribution of products, but when the height is decreased to $5 \mathrm{~mm}$, they will decrease the size of products while increasing the width of size distribution. In future work, more parameters will be changed to study the influence the parameters such as particle feed rate, binder concentration and spray rate. To describe the continuous spray agglomeration, process a stochastic modelling approach based on a Monte Carlo method will be developed and compared with the experimental results.

\section{Acknowledgements}

The authors gratefully acknowledge the funding of this work by the China Scholarship Council (NO. 201608130097). 


\section{Nomenclature}

$\begin{array}{lll}\mathrm{T} & \text { temperature } & { }^{\circ} \mathrm{C} \\ \dot{\mathrm{m}} & \text { mass flow rate } & \mathrm{g} / \mathrm{min} \\ \mathrm{X}_{10,3} & \text { particle size Q3 }\left(\mathrm{x}_{10}\right)=0.1 & \mathrm{~mm} \\ \mathrm{X}_{50,3} & \text { particle size Q3 }\left(\mathrm{x}_{50}\right)=0.5 & \mathrm{~mm} \\ \mathrm{X}_{90,3} & \text { particle size Q3 }\left(\mathrm{X}_{90}\right)=0.9 & \mathrm{~mm}\end{array}$

Greek letters

o standard deviation $\quad \mathrm{mm}$

Subscripts

$\begin{array}{ll}\mathrm{a} & \text { air } \\ \mathrm{b} & \text { binder }\end{array}$

\section{References}

[1] Ennis, B. Agglomeration and size enlargement session summary paper. Powder Technology 1996, 88, 203-225.

[2] Litster, J.; Ennis, B. The Science and Engineering of Granulation Processes; Kluwer Academic Publishers, 2004.

[3] Thielmann, F.; Naderi, M.; Ansari, M.; Stepanek, F. The effect of primary particle surface energy on agglomeration rate in fluidized bed wet granulation. Powder Technol 2008, 181, 160-168.

[4] Terrazas-Velarde, K.; Peglow, M.; Tsotsas, E. Kinetics of fluidized bed spray agglomeration for compact and porous particles. Chemical Engineering Science 2011, 66(9), 1866-1878.

[5] Dadkhah, M.; Tsotsas, E. Influence of process variables on internal particle structure in spray fluidized bed agglomeration. Powder Technology 2014, 258, 165-173.

[6] Hussain, M.; Kumar, J.; Tsotsas, E. Modeling aggregation kinetics of fluidized bed spray agglomeration for porous particles. Powder Technology 2015, 270, 584-591.

[7] Tsotsas, E. Influence of drying kinetics on particle formation: A personal perspective, Drying Technology 2012, 30:11-12, 1167-1175. 